\title{
Against the Current: Wilder Penfield, the Frontal Lobes and Psychosurgery
}

\author{
Richard Leblanc
}

\begin{abstract}
Psychosurgery refers to the surgical interruption of the white matter fibres joining the frontal cortex to the remainder of the cortical mantle and to the thalamus, in an attempt to mitigate the manifestations of psychosis. It reached its heyday following World War Two and was abandoned with the introduction of major tranquilisers such as chlorpromazine. Wilder Penfield, unlike most of his contemporaries, had a jaundiced view of psychosurgery. This paper addresses Penfield's early experience with experimental, penetrating brain trauma and with the surgical resection of frontal, epileptogenic lesions, which explain his antagonism towards psychosurgery.

RÉSUMÉ: À contre-courant : Wilder Penfield, les lobes frontaux et la psychochirurgie. La psychochirurgie consiste notamment en l'interruption chirurgicale des fibres de la substance blanche reliant le cortex frontal au reste du manteau cortical et au thalamus, et ce, pour tenter d'atténuer les manifestations de la psychose. Cette technique a atteint son apogée à la suite de la Deuxième Guerre mondiale pour être ensuite délaissée avec l'introduction des principaux tranquillisants, par exemple la chlorpromazine. À la différence de la plupart de ses contemporains, Wilder Penfield ne voyait pas d'un très bon œil la psychochirurgie. Cet article entend aborder les premiers travaux expérimentaux de Penfield portant sur les traumatismes cérébraux par pénétration et sur la résection chirurgicale de lésions frontales épileptogènes, ce qui expliquerait son opposition à l'égard de la psychochirurgie.
\end{abstract}

Keywords: Penfield, Frontal lobes, Psychosurgery, Lobotomy

doi:10.1017/cjn.2019.48

Can J Neurol Sci. 2019; 46: 585-590

\section{INTRODUCTION}

In a series of experiments that began in 1924 at Columbia University in New York, and which ended in the laboratory of Pio del Río-Hortega in Madrid in 1927, Wilder Penfield discovered that penetrating trauma to the brain results in the formation of a complex scar, to which he referred as the meningocerebral cicatrix. ${ }^{1,2}$ This lesion is composed of reactive astrocytes and astrocytic fibrils, collagen fibres and a newly created vascular plexus that anastomoses with arteries supplying the cortex around the scar. The meningocerebral cicatrix, Penfield believed, was the cause of post-traumatic epilepsy. He also discovered that the clean, meticulously atraumatic resection of such a lesion resulted in a simple gliotic reaction at the resection margin, which was not epileptogenic. These discoveries provided the rationale for the surgical treatment of focal, post-traumatic seizures.

Penfield's earliest experiences with the surgical treatment of post-traumatic epilepsy revealed that scars sometimes involved most of a lobe. In such cases, he observed, "cerebral lobectomies even though involving large amounts of brain substance was followed by surprisingly little disturbance of function." 3 One exception, however, was the extensive resection of a lesion within a frontal lobe, which sometimes produced placidity, the inability to organise one's activities and lack of initiative. I propose that this experience, early in his career, was at the origin of Penfield's antagonism towards psychosurgery.

\section{Frontal Lobectomy, 1928-1935}

- It may be urged that to destroy a delicate instrument is not the best way to study its function ${ }^{3}$
Penfield arrived in Montreal in November 1928 to head Neurosurgery at the Royal Victoria Hospital of McGill University. One of his first patients was his own sister, who had suffered from headaches and focal motor seizures of the left arm for many years. ${ }^{4}$ These had worsened and her left hand had weakened, as her headaches became more severe and she began to have bouts of vomiting. Colin Russel, the Royal Victoria's Neurologist-in-Chief, examined her when she was 43 years old. He found that she had bilateral papilledema and hyperactive, left deep tendon reflexes. A skull x-ray revealed calcifications within the right frontal lobe, and the diagnosis of a partially calcified brain tumour was made.

Penfield performed a right frontal craniotomy under local anaesthesia in December 1928 and found a hypervascular tumour. Electrocortical stimulation around the tumour produced the patient's usual seizure, and this allowed Penfield to identify the motor strip, which had been displaced posteriorly by the mass effect of the lesion. He performed an extensive resection of the tumour and of the cerebral tissue behind it. The resection thus extended from just anterior to the motor strip to the frontal pole, from the lateral cortex to the midline and to the floor of the anterior fossa (Figure 1). This resection completed, Penfield observed that "the neoplasm had passed into the opposite hemisphere. Removal of this portion was not attempted." Thus, the

From the Department of Neurology and Neurosurgery, Montreal Neurological Institute and McGill University, Montreal, Canada

Received January 24, 2019. Final Revisions Submitted April 6, 2019. Date of AcCePtance April 8, 2019.

Correspondence to: Richard Leblanc, MD, Montreal Neurological Institute, 3801 University Street. Montreal, QC, H3A 2B4, Canada. Email: richard.leblanc@mcgill.ca 


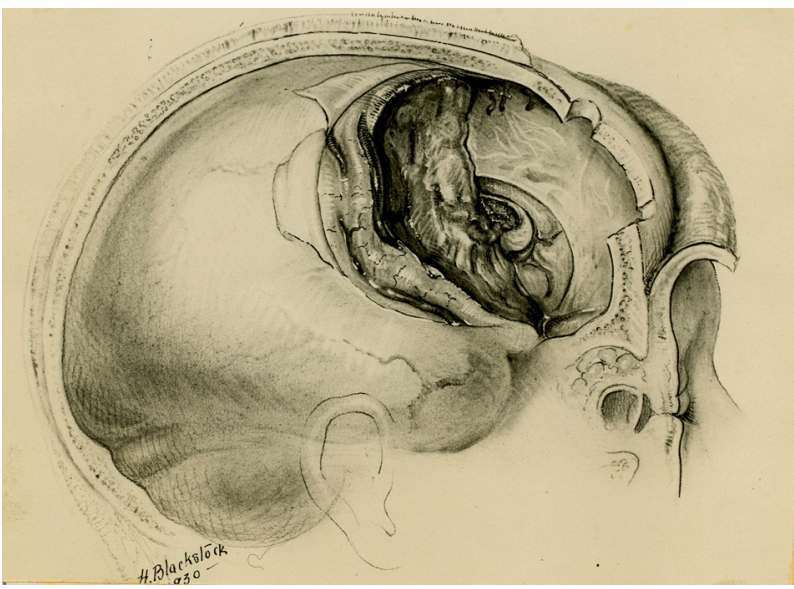

Figure 1: Drawing of the right frontal resection that Penfield performed on his sister. The convolution at the posterior margin of the resection is the motor strip. The left cingulate gyrus, the pericalossal branch of the left anterior cerebral artery and the genu of the corpus callosum are seen at the medial aspect of the resection cavity. Note that the tumour had invaded the corpus callosum. Source: Penfield archives, Osler Library of the History of Medicine, McGill University.

tumour had invaded both frontal lobes, a fact which Penfield did not mention in subsequent presentations of this case.

Despite the length of the procedure -6 hours - and a near fatal intraoperative haemorrhage, the patient quickly recovered from surgery, and her convalescence was uneventful. She had no neurological deficits when she left the hospital and, as Penfield noted, she "discharged her duties as mother and wife." There were no "immediate mental symptoms." Penfield first presented her case in 1930 and attributed the absence of any frontal lobe deficits to "the fact that other portions of the brain had taken over the function of this lobe during the very slow growth of the tumour."4

Penfield returned to her case in 1932, in an address entitled "Functional Effects Produced by Cerebral Lobectomies." 3 Penfield now reported that since he had first presented her case, his sister had undergone post-operative $\mathrm{x}$-ray treatments, but to no avail: the tumour had progressed. She had been referred to Harvey Cushing in Boston, who resected more of the tumour, but she died some two years after Penfield had first operated upon her. In the interval, Penfield had come to realise that his sister had not been "mentally up to her own standard in looking after household arrangements," due to "a lack of capacity for planned administration." Penfield attributed this newly appreciated deficiency as "the loss of power of initiative," ${ }^{3}$ which he ascribed to the right frontal lobectomy.

Penfield also reported the cases of three other patients who had also undergone a frontal lobectomy in the same address. One patient, W.B., was discussed in detail. He had sustained a depressed fracture of the right frontal bone at the age of 16 , from which he was unconscious for over two weeks. He began having seizures six years after his injury. These were characterised by head and eye turning and loss of consciousness. Penfield had recently described this type of seizure as originating from the midfrontal lobe. ${ }^{5}$ A pneumoencephalogram demonstrated evidence of a cystic lesion in an atrophic left frontal lobe. Although Penfield does not mention this in his three reports of this case, the patient had undoubtedly suffered coup-contrecoup lesions of both frontal lobes, although his seizures originated from the left one.

Penfield performed a left frontal resection in December 1929, almost as extensive as his sister's right frontal lobectomy had been, and which cured W.B.'s seizures. His clinical examination upon follow-up did not reveal any indication of " abnormality," and he had "no complaints to make regarding his ability to live and behave in a normal way." ${ }^{3}$ W.B. felt "much more controlled" when facing situations for which he had been "very antagonistic" in the past. Nonetheless, his father, who had been his sole employer, asserted that since the cranio-cerebral trauma his son "never had a job that I didn't get for him." Penfield concluded from this that W.B. "has lost initiative: not all of it, but much of it." ${ }^{3}$ It was also noted that W.B. had difficulty with simple mental arithmetic, which Penfield attributed to difficulty thinking.

Penfield also reported the cases of two other patients who had undergone frontal resections with no apparent cognitive or behavioural consequences.

Penfield concluded from these four cases that extensive frontal lobectomies "are followed by surprisingly little disturbance of function, and that those that do occur are limited to "thinking and initiative." One might also add placidity, exemplified by W.B.'s post-operative behaviour, to the effects of frontal lobe resection. ${ }^{3}$ Placidity and lack of initiative would later be appreciated as the hallmarks of frontal lobotomy. ${ }^{6}$

Penfield published three of these cases in a paper entitled "The frontal lobe in man: a clinical study of maximum removals," in Brain in March 1935. ${ }^{7}$ The paper brought the physiology of the frontal lobe to the attention of an international audience, and it is considered a milestone of neurophysiology by no less an authority than Donald Hebb. ${ }^{8}$

\section{The Second International Neurological Congress, 1935}

The Brain paper was published four months before the Second International Neurological Congress, held in London, England, from 29 July to 2 August 1935 . Two special sessions are still relevant today: one on "The Epilepsies: Their Aetiology, Pathogenesis and Treatment," and the other on "The Functions of the Frontal Lobe." Penfield was invited to speak on "Epilepsy and Surgical Therapy," but despite his previous reports on the physiology of the frontal lobes, he was not asked to participate in the session addressing these structures. ${ }^{9}$ Nonetheless, most of his paper discussed the resection of epileptogenic lesions of the frontal lobes. Its purpose was to illustrate the effectiveness of surgery in arresting epileptic attacks and the safety of this form of treatment when performed under local anaesthesia with the aid of cortical mapping. Penfield concluded his address by stating, "None of the patients have suffered serious functional defects as a result of radical [i.e. complete] extirpation" of the cicatrix and its associated epileptogenic cortex. ${ }^{9}$ Taken together, the four cases reported by Penfield in 1932, and the new cases reported in London in 1935, indicated that limited resections of damaged frontal cortex were innocuous, while the untoward effects of larger resections were likely limited to apathy and lack of initiative.

Despite Penfield's exclusion from the discussion, surgery was at the forefront of the session on the "Functions of the Frontal Lobe," as Richard Brickner, a well-regarded neurologist at the New York Neurological Institute, reported the highly influential but ultimately contentious case of a patient, to whom he referred as "patient A," who had undergone bilateral frontal lobectomies that had resulted in significant cognitive and behavioural deficiencies. ${ }^{10}$

The patient had been operated upon while comatose at Johns Hopkins Hospital, Baltimore, by Walter Dandy in August 1930. Dandy had first performed a left frontal lobe resection, which 
uncovered a large, bi-frontal parasagittal meningioma. Dandy's operative technique was the opposite of Penfield's. The latter would have proceeded with a sharp dissection to avoid damaging normal cortex. Dandy, however, used a technique that was common at the time, which consisted of bluntly dissecting the tumour from the surrounding tissue with the index finger and manually removing it. Dandy's patient regained consciousness and underwent the resection of the right frontal lobe and the remainder of the tumour a few weeks later. During the procedure, Dandy had sacrificed the right anterior cerebral artery and had noticed thrombosed veins on the residual cortex.

Brickner had first reported this case in 1932, at the same meeting where Penfield had presented his initial cases of frontal resections. Brickner's conclusion after examining Dandy's patient was simply stated: bifrontal lobectomy resulted in "inattentiveness, distractibility, impairment of retention and of learning ability, lack of initiative, or apathy," and disinhibition. ${ }^{10}$ Brickner presented the case again at the 1935 London meeting and published it in the following year. ${ }^{11}$ By then, patient $\mathrm{A}$ was hostile, aggressive and showed little restraint. In addition, his verbal expression was hesitant, he substituted one word for another and he had a tendency to use incorrect terms and neologisms. Brickner concluded from these and other nonspecific symptoms that the surgery had resulted in a failure of integration of various elements of behaviour and cognition.

John Fulton and Carlyle Jacobsen, of Yale University, gave a short paper during the open session of the Second International Neurological Congress. This paper is often cited as having influenced Egas Moniz to perform frontal leucotomies in his patients, but a careful reading of the published abstract does not support this claim. ${ }^{12}$ What Fulton and Jacobsen reported at the London meeting was that resection of the frontal associative areas in non-human primates results in "severe impairment of recent memory and behavioural adaptation dependent upon this ability." If Moniz had indeed been influenced by the Yale researchers, it is much more likely to have been by a paper that Jacobsen published in January 1935, before this meeting. In it, Jacobsen described how he had created an "experimental neurosis" in a monkey referred to as "Becky," by repeatedly having her try to perform a task that was too complicated for her to master. This caused her to have what Jacobsen called "temper tantrums," during which she whimpered, "rolled on the floor, defecated and urinated." ${ }^{13}$ These responses no longer occurred following bilateral lobectomy. Experimental neurosis had been cured by surgery.

Egas Moniz and Almeida Lima were present when Brickner and Fulton and Jacobsen read their papers. Moniz, a neurologist, at one time credited Brickner, and at another time Fulton and Jacobson, as having inspired him to prevail upon Lima, a neurosurgeon, to perform bilateral prefrontal leucotomies in patients whose symptoms were similar to Becky's experimental neurosis. This narrative, however, appears to have been an afterthought, as Moniz had been considering the role of the frontal lobe in patients for some years before the London meeting, and he mentions neither Brickner, nor Fulton and Jacobsen, in his original papers and monographs on the subject. ${ }^{14-18}$

Whatever their motivation, Moniz and Lima performed the first frontal leucotomy in man in November 1935. A transverse incision of the scalp was made towards the posterior aspect of the frontal lobe and a skin flap was reflected anteriorly towards the forehead. A burr hole was placed on each side of the midline, a few centimetres from the midline. A blunt needle was inserted through each burr hole through the frontal cortex into the depths of the subcortical white matter. Absolute alcohol was then injected through the needle to disintegrate the white matter bundles connecting the frontal cortex to other cortical areas and the thalami. Moniz and Lima quickly abandoned this method in favour of one wherein a leucotome with a thin wire loop at its end was inserted up to four times through each burr hole, and turned $360^{\circ}$ to transect the white matter. ${ }^{14,17}$

Moniz and Lima reviewed their experience after operating on 20 patients in a series of papers and presentations in French, between February and April 1936 (Appendix). After describing early postoperative complications similar to those observed by Brickner, they reported that the surgery had mitigated the symptoms of delirium in their patients. ${ }^{14-17}$ Moniz published his first account in English in 1937, in which he concluded, "Prefrontal leucotomy is a simple operation, always safe, which may prove to be an effective surgical treatment in certain cases of mental disorder." 19

Walter Freeman and James Watts performed their first leucotomy on 14 September 1936, using Moniz's technique. ${ }^{20}$ They quickly modified their approach by inserting a thin, spatula-like instrument through bilateral burr holes placed $4 \mathrm{~cm}$ above the anterior aspect of the zygomatic arch, and transecting the subcortical white matter through a vertical sweeping motion. They referred to this procedure as a lobotomy. ${ }^{21}$

\section{Hebb and Penfield, 1937-1940}

Prefrontal lobotomy was anathema to Penfield. He had demonstrated in his address to the Second International Neurological Conference that the careful resection of a cortical scar and its associated epileptogenic cortex, performed under local anaesthesia with the aid of cortical mapping and with a cooperative patient, was safe, did not produce a new epileptic scar and often resulted in a cure or significant mitigation of a patient's seizure disorder. ${ }^{22}$ The same could not be said of prefrontal lobotomy, a procedure that recalled Penfield's experiments in the 1920s. Penfield would have seen multiple, blind brain perforations and haphazard transections within the depth of the white matter as causing excessive damage in an otherwise healthy brain. Thus, referring to Freeman and Watts' early reports, Penfield concluded, "Their surgical procedure seems such as to produce extensive scar formation and vascular change, which might account for the observed mental phenomena." 23

The arrival of Donald Hebb at McGill University in 1937 provided the opportunity to study the effects of frontal ablations in a quantitative manner. Hebb reported in 1939 the cases of six patients on whom Penfield had performed large left or right frontal resections. His purpose in studying these patients was to try and establish a correlation between the volume of the tissue resected and the post-operative IQ scores. ${ }^{24,25}$

Hebb was unable to establish such a relationship because all of the patients' test results improved after surgery, or remained within the normal range. Hebb therefore concluded, "these results are interpreted to mean that any effect of frontal lobectomy upon intelligence test performance must be relatively small." ${ }^{24}$ Nonetheless, he observed that that there was a dissociation between intelligence, which remained unaffected, and executive function, which was deficient. Furthermore, Hebb noticed that one of the patients had become mildly disinhibited in her social and personal behaviour following surgery. 


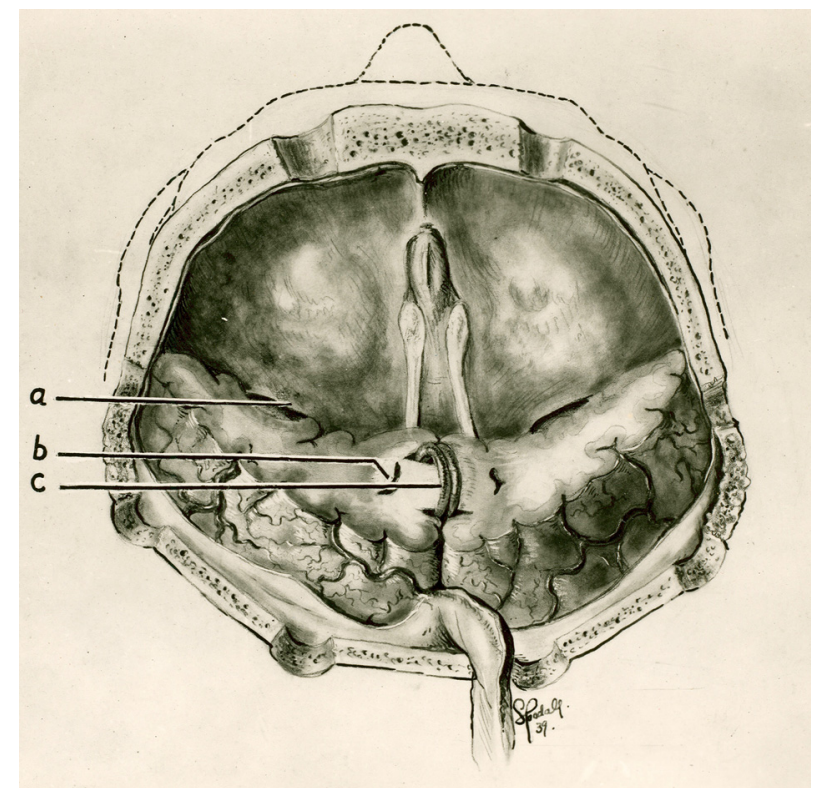

Figure 2: Drawing of the extent of the bifrontal resection that Penfield performed in patient K.M. The letter " $a$ " represents the sphenoid ridge. The letter " $b$ " indicates that the resection extended to the anterior horns of the lateral ventricles, and the letter " $c$ " illustrates that the pericallosal arteries are undamaged as they curve around the genu of the corpus callosum. Source: Penfield archives, Osler Library of the History of Medicine, McGill University.

Hebb and Penfield encountered a singular case, which they reported in 1940, of a patient who had become epileptic following a head injury and in whom Penfield resected a meningocerebral cicatrix that extended across the midline into both prefrontal lobes $^{23}$ (Figure 2).

Apart from intractable seizures, the patient's injury had rendered him "irresponsible, childishly stubborn, reckless and forgetful." Hebb found that the patient's post-operative scores on psychometric tests were higher than the pre-operative scores, and his memory had improved. Similarly, his behaviour had also changed following surgery, as he was no longer so easily distracted or lacking in restraint.

Penfield ascribed the patient's pre-operative cognitive and behavioural difficulties to the nociferous influence of the meningocerebal cicatrix upon the surrounding cortex and to the unrestrained epileptic attacks that it had provoked. The resection of the scar and of the cortex under its influence, Penfield contended, had resulted in the post-operative improvements noted on Hebb's tests, and in the patient's behaviour. "It is clear," Penfield wrote, "that the improvement is to be ascribed to a decrease of epileptogenic activity, not to removal of cerebral tissue as such." ${ }^{23}$ Hebb and Penfield concluded that their patient had improved post-operatively, while Brickner's patient had deteriorated, because the unresected frontal tissue in Brickner's patient had been damaged by Dandy's operation, wherein the left anterior cerebral artery had been sacrificed, the cortical veins were thrombosed and Broca's area had been obviously compromised. Similarly, Hebb and Penfield ascribed the complications of Freeman and Watts' patients to post-operative damage to the brain caused by the very nature of their procedure. No further reason needs be sought for Penfield's antagonism to frontal lobotomy than the inescapable damage to the brain produced by the procedure (Figure 3).

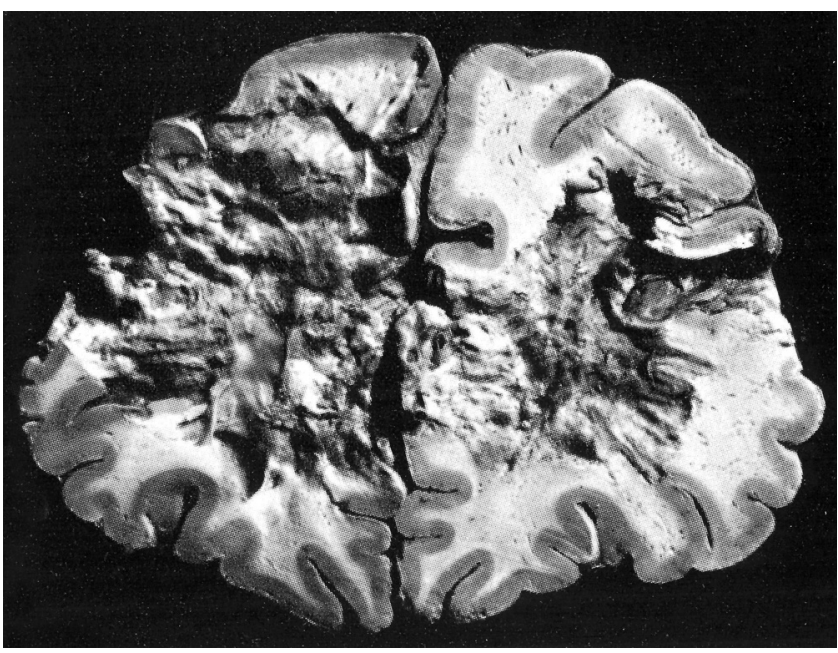

Figure 3: Post-mortem photograph of the brain of a patient who died following prefrontal lobotomies performed by Freeman and Watts. The brain had been cut in the coronal plain at the level of the lobotomies. The lobotomies produced extensive damage and cavitation of the white matter and destruction of the cortex through which the instrument used for the lobotomies had been introduced. Source: Figure 57 from Ref. [26].

\section{Gyrectomy, 1944-1947}

Despite its widespread use, frontal lobotomy remained a subject of concern to Penfield and others. ${ }^{6}$ Penfield proposed to Ewen Cameron, then a distinguished psychiatrist who in 1943 had become the first Head of the Department of Psychiatry at McGill University, that they embark on a project to see if they could mitigate the complications attendant to frontal lobotomy. Penfield would perform a restrictive resection of the frontal cortical areas, to which he initially referred to as a convolectomy, and subsequently as a gyrectomy, in an attempt to find "a procedure which might have the same therapeutic effect as [leucotomy], and yet preserve the function of more of the frontal cortex." 27,28 The operations were performed upon seven patients and were performed in late 1944 and early 1945 . The results were presented to the Association for Research in Nervous and Mental Disease in $1947 .^{28}$

The procedure consisted of the resection of a number of gyri in Brodmann's area 10 of the mid-frontal regions, which were felt to be the main projection areas for the white matter fibres originating in the thalamus. The results were disastrous. Two patients subsequently underwent lobotomy and one required readmission to hospital because of psychiatric deterioration. Three patients who had not been epileptic before gyrectomy became so after surgery and underwent further cortical resection in an attempt to alleviate their seizures. Penfield concluded from this experience that "bilateral frontal gyrectomy is a difficult, long, and somewhat dangerous procedure." 28 This statement also marks the end of Penfield's only attempt at a surgical cure for psychosis.

\section{Third World Congress of Psychiatry, 1961-1962}

Bifrontal leucotomy continued to be performed and was a subject of the Third World Congress of Psychiatry, held in Montreal in June 1961, where Freeman reported that one-third of the 3000 patients that he and Watts had operated upon had improved enough to be discharged from hospital. ${ }^{29}$ This, however, was in the absence of a control group. 
The best controlled study of the effects of prefrontal lobotomy was reported in 1962 by Kenneth McKenzie, the Head of Neurosurgery at the University of Toronto, and the psychiatrist G. Kaczanowski, in a paper entitled "Prefrontal Leucotomy: A Five-Year Controlled Study." 30 McKenzie and Kaczanowski found no difference in the proportion of patients well enough to be discharged from hospital following lobotomy, compared to an equal number of patients hospitalised in the same facility who had been spared this procedure. Approximately one-third of patients in each group were discharged from hospital, the same proportion that Freeman had reported in his uncontrolled experience. Thus, lobotomy proved to be no more beneficial than medical management, such as it was, for institutionalised, psychotic patients. "The conclusion is inescapable," McKenzie and Kaczanowski wrote, "that prefrontal leucotomy ... did not lead to any significant ... rate of remission which would not have been expected ... without the operation." The significance of McKenzie's study, however, was moot, since chlorpromazine had come into clinical use nearly a decade before, largely through the efforts of Heinz Lehmann at McGill University. ${ }^{31}$

\section{Discussion}

Penfield opened the symposium on gyrectomy with these words: "Frontal lobotomy, or leukotomy, has found a place in the therapy of certain psychiatric conditions, in spite [emphasis added] of the inevitable sacrifices which the patient must make. These sacrifices occur in the field of personality as well as intellectual ability." 28 Penfield's language is restrained, but his meaning is clear: he is not prepared to impose these sacrifices on his patients, as witnessed by his refusal to include lobotomy in his clinical practice, and his search for a less disabling procedure in gyrectomy.

The practice of frontal lobotomy is now mentioned only to be condemned. As one thoughtful commentator wrote, "by psychosurgery [i.e. lobotomy] an organic brain-defect syndrome has been substituted for the psychosis, but the psychosis has not been cured." 6 This summarises Penfield's attitude towards bifrontal lobotomy as well: he knew from his experimental studies, done decades before, that the blind destruction of cerebral tissue created a new, pathological lesion, and from published reports that lobotomy resulted in alterations of personality and behaviour without producing a cure. Penfield attempted to develop a procedure, "gyrectomy," directed at the cortical tissue that was disconnected by lobotomy, with the hope of avoiding the complications of the latter. The procedure failed; he reported his results to the premier neurological society of the time, he abandoned the procedure and, despite its growing popularity, he maintained animus towards frontal lobotomy.

Ernest Spiegel and Henry Wycis, at Temple University, shared Penfield's concerns with the destructive effects of frontal lobotomy. As Spiegel later recalled, "In the winter of 1947, I watched a prefrontal lobotomy performed and I was appalled by the resulting extensive brain damage and by the severe personality changes." ${ }^{, 32}$ This experience led Spiegel and Wycis to devise a stereotactic method of targeting the medial nucleus of the thalamus for use "in psychosurgery ... in order to reduce the emotional reactivity by a procedure much less drastic than frontal lobotomy." 33 This led to the development of stereotactic surgery as we know it today.
Penfield's reasons for conceiving of gyrectomy as a less traumatic substitute for leucotomy were based on his understanding of the anatomy and physiology of the frontal lobes, and on the damaging effects of blind, penetrating trauma on the brain. Ultimately, Penfield was driven by a desire to use his skills as a surgeon to help ease the suffering of patients for whom medicine had little to offer. But, as we have all come to realise, the desire to do well by our patients is no substitute for a well-designed clinical trial.

Interest in the function of the frontal lobes continued well after frontal lobotomy was abandoned, and our understanding of the role of the frontal lobes in human behaviour went hand in hand with the development of specific psychometric tests devised to study their function. Many of these resulted from Brenda Milner's study of Penfield's patients with frontal lobe epilepsy. ${ }^{34}$

\section{APPENDIX}

Egas Moniz and Almeida Lima reported the effects of their first experiences with frontal leucotomy during the 6 February 1936 meeting of the Société de Neurologie-the French Neurological Society. A summary of their presentation and of the discussion that followed was published in the April 1936 issue of L'Encéphale, a French journal of neurology and psychiatry. ${ }^{15}$ The very distinguished French neurosurgeon Clovis Vincent was asked to comment on Moniz and Lima's presentation. The summary of Moniz and Lima's address of 6 February 1936 to the Société de Neurologie, and of Vincent's comments, are translated below:

Symptoms of the prefrontal lobe, by Messrs. Egaz [sic] Moniz and Almeida Lima (of Lisbon):

Messrs. Egaz [sic] Moniz and Almeida Lima stress the importance of the prefrontal lobe in psychical life. They show that the syndromes of delirium often disappear after surgical interventions and define the symptomatology of the prefrontal lobe. The latter is made up of general symptoms - modification of temperature, vomiting, somnolence; of neurological disturbances - motor disturbances, trismus, bodily rotation, persisting sphincteric disturbances; of ocular disturbances - nystagmus, Argyll-Robertson [pupils], myosis; and of psychical disturbances - apathy, akinesia, catatonic posturing, opposition, mutism, childishness, a feeling of hunger. In all cases upon which the authors base their description, no disturbances of intelligence or of memory were noted.

Discussion: Mr. Clovis Vincent underlines the great interest of Mr. Egaz [sic] Moniz's presentation, but he has never encountered anything similar. He thinks that this is due to the difference of the selected cases, of the [underlying] conditions and of the [surgical] techniques [emphasis added].

\section{Disclosures}

The author has no conflicts of interest to declare.

\section{REFERENCES}

1. del Río-Hortega P, Penfield WG. Cerebral cicatrix: the reaction of neuroglia and microglia to brain wounds. Bull Johns Hopkins Hosp. 1927;41:278-303.

2. Leblanc R. Radical treatment - Wilder Penfield a life in science. Montreal and Kingston: McGill-Queen's University Press; 2019 (in press). 
3. Penfield W, Evans J. Functional effects produced by cerebral lobectomies. Ass Res Nerv Ment Dis. 1934;352-77.

4. Penfield W. Classification of brain tumours and its practical application. BMJ. 1931;1:337-42.

5. Penfield W, Gage L. Cerebral localization of epileptic manifestations. Arch Neurol Psychiat. 1933;30:712-3.

6. Hoffman JL. Clinical observations concerning schizophrenic patients treated by prefrontal leucotomy. New Engl J Med. 1949;241:233-6.

7. Penfield $\mathrm{W}$. The frontal lobe in man: a clinical study of maximum removals. Brain. 1935;58:115-33

8. Compston A. The frontal lobe in man: a clinical study of maximum removals. Brain. 2006;129:827-9.

9. Penfield W. Epilepsy and surgical therapy. Arch Neurol Psychiat. 1936;36:449-82.

10. Brickner RM. An interpretation of frontal lobe function based upon the study of a case of partial bilateral frontal lobectomy. Localization Funct Cerebral Cortex. 1934;13:259-351.

11. Brickner RM. The intellectual functions of the frontal lobes. Toronto: Macmillan; 1936.

12. Fulton JF, Jacobsen CF. The functions of the frontal lobes: a comparative study in monkeys, chimpanzees, and man. Abstracts of the Second International Neurological Congress. London; 1935, pp. 70-71.

13. Jacobsen CF, Wolfe JB, Jackson TA. An experimental analysis of the functions of the frontal associative areas in primates. J Nerv Ment Dis. 1935;82:1-14.

14. Moniz E, Lima A. Premiers essais de psycho-chirurgie. Technique et résultat. Lisboa Medica. 1936;13:152-61.

15. Moniz E, Lima A. Symptômes du lobe préfrontal. L'`Encéphale. 1936;1:306.

16. Moniz E, Essai d'un traitement chirurgical de certaines psychoses. Bulletin national de l'Académie de Médecine (Paris). 1936;115:385-92.

17. Moniz E. Tentatives operatoires dans le traitment des psychoses. Paris: Masson \& Cie; 1936.

18. Berrios GE. The origins of psychosurgery: Shaw, Burckhardt and Moniz. Hist Psychiat. 1997;8:61-81. [72-74].

19. Moniz E. Prefrontal leucotomy in the treatment of mental disorders. Am J Psychiat. 1937;93:1379-85.
20. Freeman W, Watts JW. An interpretation of the functions of the frontal lobes based on the observation in forty-eight cases of prefrontal lobotomy. Yale J Biol Med. 1939;11:527-39.

21. Freeman W, Watts JW. Prefrontal lobotomy: the surgical relief of mental pain. Bull N Y Acad Med. 1942;18:794-812.

22. Penfield W. Epilepsy and surgical therapy. Arch Neurol Psychiat. 1936;36:449-82.

23. Hebb DO, Penfield W. Human behavior after extensive bilateral removal from the frontal lobes. Arch Neurol Psychiatry. 1940;42:421-38.

24. Hebb DO. Intelligence in man after large removals of cerebral tissue: report of four left frontal lobe cases. J Gen Psychiat. 1939;21:73-87.

25. Hebb DO. Human intelligence after removal of cerebral tissue from the right frontal lobe. J Gen Psychiat. 1941;25:257-65.

26. Freeman W, Watts JW, Hunt T. Psychosurgery: intelligence, emotion and social behavior following prefrontal lobotomy for mental disorders. London: Baillière, Tindall \& Cox; 1942.

27. Montreal Neurological Institute annual report, 1944-1945: 31-2, 188.

28. Penfield W. Bilateral frontal gyrectomy and postoperative intelligence. Ass Res Nerv Ment Dis. 1948;27:519-34

29. Freeman W. Psychosurgery a quarter of a century later. In: Proceedings of the Third World Congress of Psychiatry, Montreal, Canada, June 4-10, 1961, Vol 1. Toronto: University of Toronto Press; 1962, p. 141.

30. McKenzie K, Kaczanowski G. Prefrontal leukotomy: a five-year controlled study. Can Med Assoc J. 1964;91:1193-6.

31. Lehmann HE, Hanrahan GE. Chlorpromazine, new inhibiting agent for psychomotor excitement and manic states. Arch Neurol Psychiatry. 1954;71:227-37.

32. Spiegel EA cited in Rzesnitzek L, Hariz M, Krauss J. The origins of human functional stereotaxis: a reappraisal. Stereotact Funct Neurosurg. 2019 Feb;13:1-6. doi: 10.1159/000496157

33. Spiegel EA, Wycis HT, Marks M, Lee AJ. Stereotaxic apparatus for operations on the human brain. Science. 1947;106:349-50.

34. Milner B. Aspects of human frontal lobe function. In: Jasper HH, Riggio S, Goldman PS, editors. Epilepsy and the functional anatomy of the frontal lobe. New York: Raven Press; 1995, pp. $67-84$. 